\title{
Fortified food loophole or natural health product?
}

Published at www.cmaj.ca on Apr. 14

$\mathrm{T}$ he juice aisle has a secret. Some of its juices are not just juices; they are also "natural health products" fortified with vitamins and minerals under licenses granted by Health Canada's Natural Health Products Directorate.

Also sporting licenses are such content-boosted products as vitamin-enhanced waters, chewing gums and energy drinks.

To date, 32 foods carry the Natural Health Products Directorate's explicit seal of approval and, according to Health Canada spokesperson David Thomas, another 857 product licence applications for "health products in a food format" are awaiting evaluation.

It's the product of what health professionals are calling a fortification loophole. Although the existing food regulatory framework prohibits discretionary fortification, the natural health products framework does not.

The double standard is not lost on industry, says Ronald Doering, food lawyer and past president of the Canadian Food Inspection Agency. "If one part of Health Canada does not think the scientific evidence is strong enough, then companies will just go next door to another office at Health Canada and sell the products as natural health products, where the standard is not the same and sweeping claims are already being made."

Even Health Canada appears to agree that the double standard has prompted manufacturers to bolt for the natural health products camp. As William Yan, acting director of Health Canada's bureau of nutritional sciences, told a February meeting of stakeholders interested in discretionary fortification, "some members of the food industry have sought faster market access for fortified foods by applying for product licenses as natural health products."

"Health Canada is intending to transition most of these products to the food regulatory framework over a period of time," Yan told delegates to the session, entitled "The Path Forward." But before

Still, it is allowing fortification of natural health products and some of those are in a food format, for which there are special considerations.

Departmental "guiding principles," governing product approval state that "if a product has a historical pattern of use as a food or if the public perception associated with the use of a product in the marketplace is that it is a food, these are indications that the product is a food," rather than a natural health product (www.hc-sc .gc.ca/dhp-mps/prodnatur /legislation/docs/food-nhp-ali ments-psn-guide-eng.php).

A similar distinction between conventional foods and natural health products is reflected in the department's "regulatory impact analysis" statement: "The NHP [natural health products] definition does not include conventional foods. Further, the definition is not intended to capture a product in a food medium which might otherwise fall within the definition (because

it can do so, "changes to the food regulatory framework are required to support innovation and permit the sale of products that are safe and effective."

Last year, Health Canada proposed to allow vitamin and mineral additives, such as iron and calcium in high-calorie junk foods (CMAJ 2009. DOI:10.1503/ cmaj.090897). It is also leading an international charge to amend world food standards to allow industry more discretion in the fortification of foods through the addition of vitamins and minerals (CMAJ 2010. DOI:10.1503 /cmaj.109-3185).

But Health Canada withdrew the proposal to allow fortification of junk foods after public health advocates argued that it would promote the consumption of less healthy foods and expose the population to potential risks associated with chronic nutrient overconsumption. it contains vitamins or minerals, for example) if that food is primarily consumed to provide nourishment, nutrition or hydration, or to satisfy hunger, thirst or a desire for taste, texture or flavour" (www.hc-sc.gc.ca/dhp-mps/prodnatur /legislation/actslois/prodnatur/propose 2_regula-regle_doc10-eng.php).

The documents suggest that conventional foods cannot be licensed as natural health products as consumers may not draw a distinction between fortified and nonfortified options, and thus may choose to consume the fortified option freely without paying attention to dosage.

The line gets blurry, though, on products such as juices. As Health Canada itself acknowledged in an email, "water and juice have historical patterns of use as foods. Health Canada further acknowledges that the public 
perception of these products, unless counteracted in some way (such as with proper labelling), could be that they are foods."

Health Canada argues that there is a measure of flexibility built into the guiding principles and regulations, allowing for interpretation.

"The Guidance Document lists a number of factors that help determine if a product should be classified as a food or a NHP. Historical use and public perception are factors that guide the decision; however, no one factor is decisive," Thomas wrote in an email. To avoid risk,
Health Canada added that it "encourages all consumers to carefully read the labels of all health products they consume and to follow label instructions."

Consulting dietitian and author Rosie Schwartz thinks the case for natural health products in supermarkets is inherently flawed.

"If you can't put it on the shelf as a food, then it shouldn't be on the supermarket shelf," she says, adding that risks may accrue as a result of unintentional nutrient overconsumption. "We do know that too much of a good thing can be a problem with some nutrients."
Products with historical use patterns as foods will be treated as such by consumers, says Charlene Elliott, associate professor of communication and culture at the University of Calgary in Alberta. "Won't consumers treat NHP juices and NHP waters as substantially equivalent to juice and water? Why wouldn't they? It looks like water; it tastes like water. Why would you shift your levels of consumption?" - Yoni Freedhoff MD, Ottawa, Ont.

DOI:10.1503/cmaj.109-3228 